\title{
Treatment algorithm in cancer-associated thrombosis: Canadian expert consensus
}

\author{
M. Carrier MD MSc, ${ }^{*}$ N. Blais $\mathrm{MD} \mathrm{MSc}^{\dagger}$ M. Crowther $\mathrm{MD} \mathrm{MSc}^{\ddagger}$ P. Kavan MD PhD, ${ }^{\S}$ G. Le Gal MD PhD, ${ }^{*}$ \\ O. Moodley MD, II S. Shivakumar MD, ${ }^{\#}$ V. Tagalakis MD MSc, ${ }^{* *}$ C. Wu MD, ${ }^{+\dagger}$ and A.Y.Y. Lee MD MSc ${ }^{\ddagger \neq}$
}

\begin{abstract}
Management of anticoagulant therapy for the treatment of venous thromboembolism (VTE) in cancer patients is complex because of an increased risk of recurrent vTE and major bleeding complications in those patients relative to the general population. Subgroups of patients with cancer also show variation in their risk for recurrent vTE and adverse bleeding events. Accordingly, a committee of 10 Canadian clinical experts developed the consensus riskstratification treatment algorithm presented here to provide guidance on tailoring anticoagulant treatment choices for the acute and extended treatment of symptomatic and incidental vTE, to prevent recurrent vTE, and to minimize the bleeding risk in patients with cancer.

During a 1-day live meeting, a systematic review of the literature was performed, and a draft treatment algorithm was developed. The treatment algorithm was refined through the use of a Web-based platform and a series of online teleconferences.

Clinicians using this treatment algorithm should consider the bleeding risk, the type of cancer, and the potential for drug-drug interactions in addition to informed patient preference in determining the most appropriate treatment for patients with cancer-associated thrombosis. Anticoagulant therapy should be regularly reassessed as the patient's cancer status and management change over time.
\end{abstract}

Key Words Venous thromboembolism; venous thrombosis; hemorrhage; heparin, low-molecular-weight

Curr Oncol. 2018 Oct;25(5):329-337

www.current-oncology.com

\section{INTRODUCTION}

Venous thromboembolism (VTE) is common in cancer patients, who have a risk of vTE that is increased by a factor of 4 compared with the general population, and for whom VTE is the 2nd leading cause of death after cancer progres$\operatorname{sion}^{1,2}$. However, because of an increased risk of recurrent VTE and major bleeding relative to the general population, the management of anticoagulant therapy for vTE in the cancer-patient population is complex ${ }^{3,4}$. The underlying risk for recurrent VTE and major bleeding complications varies based on patient-related risk factors as well as on tumour type, cancer stage, and anticancer treatments ${ }^{3,4}$. Treatment choices for the acute and extended treatment of VTE have to be tailored to prevent recurrence of VTE and to minimize the bleeding risk in patients with cancer.

Several treatment options-including oral vitamin $\mathrm{K}$ antagonists (VKAs), low-molecular-weight heparins (LMWHS), and direct-acting oral anticoagulants (DOACS) are available for the treatment of an acute episode of VTE.
Based on the results of trials comparing LMWH with VKA in the cancer-patient population, current clinical practice guidelines suggest using LMWH monotherapy for the acute and extended treatment of cancer-associated thrombosis (CAT) ${ }^{5,6}$. Recently, two randomized controlled trials (RCTS) comparing DoACs with LMWH for the treatment of CAT (HOKUSAI VTE Cancer and SELECT-D) were published ${ }^{7,8}$. The consensus process reported here was undertaken to develop an evidence-based risk-stratification treatment algorithm and to provide expert guidance about anticoagulation to health care professionals caring for patients with CAT.

\section{METHODS}

\section{Literature Review}

To develop the treatment algorithm, the committee used, as a starting point, the previously published 2014 Canadian consensus recommendations on the management of CAT $^{9}$. A systematic review of the literature published since 2014 
was performed using the search strategies depicted in supplemental Appendix 1.

\section{Treatment Algorithm Development}

The multidisciplinary consensus group, which included 10 physicians with expertise in the areas of hematology, medical oncology, hematologic oncology, and general internal medicine, convened in February 2018 for a 1-day live meeting, during which the results of the literature search were discussed and the first draft of the treatment algorithm was developed.

The draft treatment algorithm and meeting minutes were then uploaded to a Web-based platform [Google Docs (https://gsuite.google.com/intl/en_ca/products/docs/)] so that committee members could review the document and provide comments. The draft treatment algorithm was revised based on the resulting feedback and was finalized during a series of Web-based teleconferences held during April and May 2018, during which committee members discussed the treatment algorithm and voted to indicate their level of agreement with both the overall treatment algorithm and with specific changes made to the draft treatment algorithm. The final version of the manuscript was also peer-reviewed by an independent member of Thrombosis Canada.

\section{Role of the Funding Source}

The meetings were funded by an unrestricted grant from Pfizer Canada. The authors administered all aspects of the treatment algorithm development, and the funding source had no role in drafting, editing, or approving the treatment algorithm.

\section{RESULTS}

The PubMed-based search strategy identified 375 articles, 78 of which were considered potentially relevant. The search of the American Society of Hematology abstract database identified sixty-one abstracts, six of which were considered potentially relevant. All identified articles and conference abstracts were reviewed by the committee. Based on discussion of the evidence, the committee developed the treatment algorithm (Figure 1) to provide guidance about the selection of anticoagulation therapy in cancer patients with incidental or symptomatic acute proximal lower-limb deep vein thrombosis (DVT) or pulmonary embolism.

According to the treatment algorithm, patients considered to be at high risk of bleeding, those with active gastrointestinal (GI) or urothelial cancer, or those taking concomitant medications that would lead to potentially serious drug-drug interactions with DOACs should be treated with a therapeutic dose of extended-duration LMwH. Patients not meeting the foregoing criteria can be treated with DOACs. Other factors to consider in anticoagulant selection include patient preference, once the patient has been informed of the risks and benefits of the options and after consideration of drug costs and reimbursement, body weight, burden of cancer, burden of VTE, renal function, significant GI surgery or absorption disorders, and any other pre-existing conditions and co-medications. As
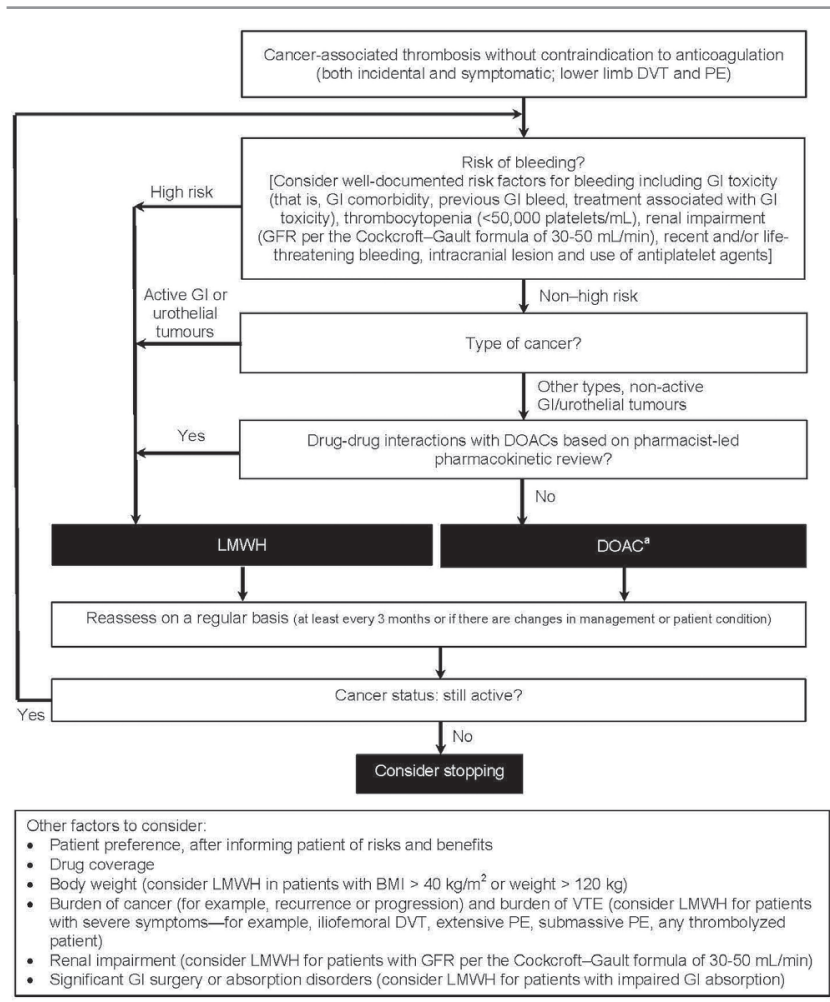

FIGURE 1 Patient risk stratification algorithm for the treatment of cancer-associated thrombosis. ${ }^{a}$ Currently, edoxaban and rivaroxaban are the only direct-acting oral anticoagulants (DOACs) with randomized controlled trial evidence in cancer-associated thrombosis, with the evidence base being stronger for edoxaban. Refer to the relevant product monograph for appropriate dosing. DVT = deep vein thrombosis; $\mathrm{PE}=$ pulmonary embolism; $\mathrm{Gl}=$ gastrointestinal; $\mathrm{GFR}=$ glomerular filtration rate; $\mathrm{DOAC}=$ direct-acting oral anticoagulant; $\mathrm{LMWH}=$ low molecular weight heparin; $\mathrm{BMI}=$ body mass index; $\mathrm{VTE}=$ venous thromboembolism.

shown in the treatment algorithm, anticoagulant therapy should be reassessed at least every 3 months-or sooner if the patient's cancer management or condition changes. The decision about duration of therapy depends largely on the cancer status of the patient and whether anticancer treatment with thrombogenic potential is ongoing.

Of the 10 committee members, $6(60 \%)$ strongly agreed with the final version of the treatment algorithm (Figure 1), and $4(40 \%)$ somewhat agreed it. No members somewhat or strongly disagreed with the proposed algorithm.

\section{DISCUSSION}

\section{Efficacy and Safety of Anticoagulants}

Based on the superior efficacy demonstrated for LMwHS compared with VKA across RCTS, LMWHS are recommended for the treatment and secondary prevention of VTE in patients with cancer (Table I). A meta-analysis of the results of all RCTS comparing LMWH with VKA for the management of CAT reported a $44 \%$ reduction in the risk of recurrent VTE [relative risk (RR): 0.56; 95\% confidence interval (CI): 0.43 to 0.74 ], without a significant increase in the risk of major bleeding (RR: 1.07; 95\% CI: 0.66 to 1.79$)^{16}$. 
TREATMENT ALGORITHM IN CANCER-ASSOCIATED THROMBOSIS, Carrier et al.

TABLE I Randomized controlled trials for the acute treatment of cancer-associated thrombosis

\begin{tabular}{|c|c|c|c|c|c|c|}
\hline $\begin{array}{l}\text { Reference } \\
\text { (study name) }\end{array}$ & $\begin{array}{l}\text { Pts } \\
(n)\end{array}$ & Intervention & Duration & $\begin{array}{c}\text { Major } \\
\text { bleeding } \\
(\%)\end{array}$ & $\begin{array}{c}\text { Recurrent } \\
\text { VTE } \\
(\%)\end{array}$ & $\begin{array}{c}\text { Death } \\
(\%)\end{array}$ \\
\hline \multicolumn{7}{|c|}{$\begin{array}{l}\text { Low molecular weight heparin }(L M W H) \\
\text { compared with vitamin } K \text { antagonist }\end{array}$} \\
\hline Meyer et al., $2002^{10}$ & 67 & Enoxaparin $1.5 \mathrm{mg} / \mathrm{kg}$ daily & 3 Months & 7 & 3 & 22.7 \\
\hline (CANTHANOX) & 71 & Vitamin $\mathrm{K}$ antagonist & & 16 & 4.2 & 11.3 \\
\hline \multirow[t]{2}{*}{$\begin{array}{l}\text { Lee et al., } 2003^{11} \\
\quad \text { (CLOT) }\end{array}$} & 336 & $\begin{array}{l}\text { Dalteparin } 200 \mathrm{IU} / \mathrm{kg} \text { daily } \\
\text { or } 1 \text { month, and then } 150 \mathrm{IU} / \mathrm{kg}\end{array}$ & 6 Months & 4 & 9 & 39 \\
\hline & 336 & Vitamin $\mathrm{K}$ antagonist & & 6 & 17 & 41 \\
\hline Deitcher et al., 2006 ${ }^{12, a}$ & 29 & Enoxaparin $1 \mathrm{mg} / \mathrm{kg}$ daily & 3 Months & 6.5 & 6.9 & 6.5 \\
\hline \multirow{2}{*}{ (ONCENOX) } & 32 & Enoxaparin $1.5 \mathrm{mg} / \mathrm{kg}$ daily & & 11.1 & 6.3 & 19.4 \\
\hline & 30 & Vitamin $\mathrm{K}$ antagonist & & 2.9 & 10 & 8.8 \\
\hline Hull et al., $2006^{13}$ & 100 & Tinzaparin 175 IU/kg daily & 3 Months & 7 & 6 & 19 \\
\hline (LITE) & 100 & Vitamin $\mathrm{K}$ antagonist & & 7 & 10 & 20 \\
\hline Lee et al., $2015^{14}$ & 449 & Tinzaparin $175 \mathrm{IU} / \mathrm{kg}$ daily & 6 Months & 2.7 & 7.2 & 33 \\
\hline$(\mathrm{CATCH})$ & 451 & Vitamin $\mathrm{K}$ antagonist & & 2.4 & 10.5 & 31 \\
\hline
\end{tabular}

Direct-acting oral anticoagulant

compared with LMWH (completed)

\begin{tabular}{|c|c|c|c|c|c|c|}
\hline \multirow{4}{*}{$\begin{array}{l}\text { Raskob et al., } 2018^{7} \\
\text { (HOKUSAI VTE Cancer) }\end{array}$} & 522 & LMWH for 5 or more days, & 12 Months & 6.9 & 7.9 & 39.5 \\
\hline & & and then edoxaban $60 \mathrm{mg}$ daily & & & & \\
\hline & 524 & Dalteparin 200 IU/kg daily & & 4.0 & 11.3 & 36.6 \\
\hline & & for 1 month, and then $150 \mathrm{IU} / \mathrm{kg}$ daily & & & & \\
\hline \multirow{3}{*}{$\begin{array}{l}\text { Young et al., } 2018^{8} \\
\text { (SELECT-D) }\end{array}$} & 203 & Rivaroxaban 15 mg twice daily & 6 Months & 6 & 4 & 25 \\
\hline & & for 3 weeks, and then $20 \mathrm{mg}$ daily & & & & \\
\hline & 203 & Dalteparin 200 IU/kg daily & & 4 & 11 & 30 \\
\hline
\end{tabular}

for 1 month, and then $150 \mathrm{IU} / \mathrm{kg}$ daily

Direct-acting oral anticoagulant

compared with $\mathrm{LMWH}$ (ongoing) ${ }^{\mathrm{b}}$

\begin{tabular}{|c|c|c|c|}
\hline \multirow{4}{*}{$\begin{array}{l}\text { NCT02746185 } \\
\text { (CASTA-DIVA) }\end{array}$} & 80 & Rivaroxaban 15 mg twice daily & 3 Months \\
\hline & & for 3 weeks, and then $20 \mathrm{mg}$ daily & \\
\hline & 80 & Dalteparin 200 IU/kg daily & \\
\hline & & for 1 month, and then $150 \mathrm{IU} / \mathrm{kg}$ daily & \\
\hline \multirow{3}{*}{$\begin{array}{l}\text { NCT02583191 } \\
\text { (CONKO-011) }\end{array}$} & 225 & Rivaroxaban 15 mg twice daily & 6 Months \\
\hline & & for 3 weeks, and then $20 \mathrm{mg}$ daily & \\
\hline & 225 & Therapeutic dose of LMWH & \\
\hline \multirow{4}{*}{$\begin{array}{l}\text { McBane et al., } 2017^{15} \\
\text { (ADAM-VTE) }\end{array}$} & 150 & Apixaban $10 \mathrm{mg}$ twice daily & 6 Months \\
\hline & & for 7 days, and then $5 \mathrm{mg}$ twice daily & \\
\hline & 150 & Dalteparin 200 IU/kg daily & \\
\hline & & for 1 month, and then $150 \mathrm{IU} / \mathrm{kg}$ daily & \\
\hline \multirow{4}{*}{$\begin{array}{l}\text { NCT03045406 } \\
\text { (CARAVAGGIO) }\end{array}$} & 584 & Apixaban 10 mg twice daily & 6 Months \\
\hline & & for 7 days, and then $5 \mathrm{mg}$ twice daily & \\
\hline & 584 & Dalteparin 200 IU/kg daily & \\
\hline & & for 1 month, and then $150 \mathrm{IU} / \mathrm{kg}$ daily & \\
\hline
\end{tabular}

a All groups started with enoxaparin $1 \mathrm{mg} / \mathrm{kg}$ twice daily for 5 days.

b The ongoing trials in this table do not constitute a complete list of relevant trials. Patient numbers represent the target enrolment, and results have not yet been reported.

Pts = patients; VTE = venous thromboembolism 
Current clinical practice guidelines also recommend the use of LMWH over DOACs for the acute and secondary prevention of cAT. Until recently, only post hoc analyses of selected low-risk patients with cancer from RCTs comparing DOACS with VKAs for the treatment of VTE were available. Those subgroup analyses suggested that DoAcs are comparable to VKAs ${ }^{17}$. A meta-analysis including 1132 patients with CAT reported that, compared with vKAs, DOACs are associated with nonsignificant reductions in the risk of recurrent VTE (37\%; RR: $0.63 ; 95 \%$ CI: 0.37 to 1.10 ) and in the risk of major bleeding (31\%; RR: $0.69 ; 95 \%$ CI: 0.34 to 1.41$)^{17}$. However, the quality of the evidence is low, given that the results were derived post hoc and lack generalizability to most patients with CAT. The cancer subgroups also had important differences in the definitions of "active" cancer and in prognostic characteristics, including the presence of metastatic disease and the use of cancer therapies. Importantly, patients who were deemed to require LMWH therapy were systematically excluded from several of the trials. Overall, the cancer patients enrolled in the studies comparing DOACs with vKAs were "healthier" than the patient populations in the CLOT and CATCH trials comparing LMWHS with VKAs ${ }^{11,14,17}$. Hence, clinical practice guidelines continue to recommend LMwH as first-line therapy for the acute and long-term management of cAT.

The publication of the HOKUSAI VTE Cancer and SELECT-D trials provides the first RCT evidence directly comparing DOACS with LMWH for the management of CAT $(\text { Table I })^{7,8}$. The open-label noninferiority HOKUSAI VTE Cancer trial randomized 1050 patients with cancer and acute symptomatic or incidental VTE to LMWH for at least 5 days, followed by edoxaban or dalteparin for a total treatment time of at least 6 months and up to 12 months 7 . Edoxaban was dosed at $60 \mathrm{mg}$ daily, with a dose reduction to $30 \mathrm{mg}$ daily in patients with a body weight of $60 \mathrm{~kg}$ or less, a creatinine clearance of $30-50 \mathrm{~mL} / \mathrm{min}$, or concomitant use of P-glycoprotein inhibitors. Dalteparin was dosed at $200 \mathrm{IU} / \mathrm{kg}$ daily for the first month and at $150 \mathrm{IU} / \mathrm{kg}$ daily thereafter, with a maximum daily dose of 18,000 IU and temporary dose reductions for patients whose platelet count declined to less than $100,000 / \mathrm{mL}$. The primary outcome, a composite of recurrent vTE or major bleeding in the 12 months after randomization, was reported for $12.8 \%$ of patients receiving edoxaban and for $13.5 \%$ of those receiving dalteparin [hazard ratio (HR): $0.97 ; 95 \%$ CI: 0.70 to 1.36 ; $p=0.006$ for noninferiority]. Rates of recurrent vTE were nonsignificantly lower for patients treated with edoxaban than for those treated with dalteparin (HR: 0.71; 95\% CI: 0.48 to 1.06), with the curves appearing to separate after the first 90 days. Rates of major bleeding complications were significantly higher with edoxaban than with dalteparin (HR: 1.77 ; 95\% CI: 1.03 to 3.04 ), with the curves appearing to separate at randomization. It is possible that some of those findings might be attributable to either or both of better adherence to edoxaban than to dalteparin, or of longer use of edoxaban (median treatment duration: 211 days with edoxaban vs. 184 days with dalteparin, $p=0.01$ ).

The open-label multicentre SELECT-D pilot trial randomized 406 cancer patients with acute vTE to either rivaroxaban or dalteparin ${ }^{8}$. During the 6-month treatment period, patients received either rivaroxaban $15 \mathrm{mg}$ twice daily for 3 weeks and then $20 \mathrm{mg}$ daily, or dalteparin $200 \mathrm{IU} /$ $\mathrm{kg}$ daily for 1 month and then $150 \mathrm{IU} / \mathrm{kg}$ daily. Doses of both drugs were adjusted or discontinued for a low platelet count or various levels of renal impairment. The primary outcome (VTE recurrence during a period of 6 months) occurred in $11 \%$ of patients taking dalteparin and in $4 \%$ of those taking rivaroxaban (HR: $0.43 ; 95 \% \mathrm{CI}: 0.19$ to 0.99 ). The reduction in the risk of recurrent vTE seems to occur beyond the initial month of treatment. The 6 -month cumulative rate of major bleeding was $4 \%$ in patients taking dalteparin and $6 \%$ in those taking rivaroxaban (HR: 1.83 ; $95 \%$ CI: 0.68 to 4.96 ), but clinically relevant non-major bleeding was significantly higher in those taking rivaroxaban (4\% vs. $13 \%$; HR: 3.76 ; 95\% CI: 1.63 to 8.69 ). Even though recurrent vTE was the primary outcome, the study protocol did not specify central adjudication of suspected vTE events ${ }^{8}$. Given the open-label design, adjudication by a central committee unaware of the treatment allocation after study completion does not mitigate the risk of investigator or reporter bias. Furthermore, the treatment-group differences in recurrent thrombotic outcomes might be the result of an imbalance in incidental pulmonary embolism rather than of symptomatic events.

In summary, the available evidence suggests that DOACs are noninferior to LMWHs, with edoxaban having the strongest evidence base. Although the similar results seen in the SELECT-D pilot study and the HOKUSAI VTE Cancer trial might suggest that the effect of DOACs in CAT could be a class effect (rather than a specific drug effect) of direct oral factor Xa inhibitors, further evidence from ongoing trials with apixaban (Table I) could help to clarify that hypothesis. No data (or known ongoing prospective studies) comparing the direct thrombin inhibitor dabigatran with LMWH for the management of CAT are available.

\section{Risk of Bleeding}

The HOKUSAI VTE Cancer and SELECT-D RCTS both reported a higher risk of major bleeding complications for patients treated with DoAcs compared with those treated with LMWH (Table I ${ }^{7,8}$. In the HokUsaI vTE Cancer trial, the difference was attributable mainly to the higher rate of upper GI bleeding in patients taking edoxaban ${ }^{7}$. Of all major bleeding episodes, $47 \%$ in patients taking edoxaban involved the upper GI system; only $14 \%$ of patients taking dalteparin experienced an upper gI bleed ${ }^{7}$. The increase in upper GI major bleeding occurred mainly in patients with a GI cancer. Similar results were seen in SELECT-D, in which approximately $45 \%(5 / 11)$ of all major bleeding episodes in rivaroxaban-treated patients were related to the GI tract $^{8}$. Similarly, most clinically relevant non-major bleeding events in patients treated with rivaroxaban involved the GI tract or urinary system ${ }^{8}$. After a safety review of the first 220 patients, the data safety monitoring committee of the SELECT-D trial noted a nonsignificant increase in major bleeding events in 19 patients with esophageal or gastroesophageal junction cancers. Patients with those cancers were subsequently excluded from enrolment. Patients with GI cancer taking DOACs therefore seem to be at particularly high risk for bleeding 7,8 .

Subgroup analyses of major bleeding in the HoKUSAI vTE Cancer safety population ${ }^{7}$ suggest that, in addition to GI cancer, other high-risk features associated with 
major bleeding complications are urothelial cancer, a creatinine clearance of $30-50 \mathrm{~mL} / \mathrm{min}$, a platelet count of 50,000-100,000/mL, use of antiplatelet agents, and 3 or more bleeding risk factors (Table II).

To determine the risk-benefit ratio when tailoring the anticoagulation management of patients with CAT, clinicians must estimate the risks of major bleeding complications compared with recurrent thrombosis. In addition to GI cancer, clinicians should also consider other tumour types (for example, urothelial cancer) and features associated with high risk for bleeding, including GI mucosal abnormalities (for example, mucositis), recent bleeding or prior major bleeding, thrombocytopenia, renal impairment, and antiplatelet use ${ }^{18-20}$. Additionally, given that the DOAcs seem to be associated with a higher risk of upper GI major bleeding episodes ${ }^{7}$, DOACs should be used cautiously in patients undergoing anticancer regimens associated with GI toxicity (Table III). The LMwHs might be safer for patients thought to be at high risk for bleeding.

\section{Drug-Drug Interactions}

Cancer patients are frequently treated with multiple anticancer therapies, and an evaluation of the potential for drug-drug interactions is therefore important when selecting the appropriate anticoagulant therapy for CAT. That evaluation includes considering the potential for any direct toxicity that might occur with the concomitant use of anticoagulant regimens and acetylsalicylic acid or nonsteroidal anti-inflammatory drugs, and any potential pharmacokinetic interactions ${ }^{23}$.

All DoAcs are substrates of P-glycoprotein ${ }^{24-26}$. Apixaban and rivaroxaban are also substrates of cytochrome P450 (CYP3A4); edoxaban and dabigatran are not. Table IV lists common drug-drug interactions associated with P-glycoprotein and CYP450 metabolism. However, assessment of the potential for clinically significant interactions is complex in patients treated with multiple medications because the various agents might compete for metabolism by a common pathway or have opposing effects (when inhibitors and inducers are both being used). Given the complexity of the therapeutic regimens used for many cancer

TABLE II Rates of major bleeding complications in patients with highrisk features in the HOKUSAI VTE Cancer trial ${ }^{7}$

\begin{tabular}{|c|c|c|c|}
\hline \multirow[t]{2}{*}{ Risk factor } & \multicolumn{2}{|c|}{ Major bleeding (\%) } & \multirow{2}{*}{$\begin{array}{c}p \\
\text { Value }\end{array}$} \\
\hline & Edoxaban & Dalteparin & \\
\hline Urothelial cancer & 13.2 & 0 & NA \\
\hline Creatinine clearance $30-50 \mathrm{~mL} / \mathrm{min}$ & 10.5 & 2.9 & NA \\
\hline Platelets $50-100 \times 10^{3} / \mathrm{mL}$ & 12.5 & 4.3 & NA \\
\hline Use of antiplatelet agents & 11.5 & 3.2 & NA \\
\hline 3 Risk factors ${ }^{a}$ & 13.5 & 4.1 & $<0.05$ \\
\hline 4 Or more risk factors ${ }^{a}$ & 10.5 & 4.2 & NA \\
\hline \multicolumn{4}{|c|}{$\begin{array}{l}\text { Defined as surgery within the preceding } 2 \text { weeks, use of antiplatelet } \\
\text { agents, primary or metastatic brain tumour, regionally advanced or } \\
\text { metastatic cancer, gastrointestinal or urothelial cancer diagnosed } \\
\text { within the preceding } 6 \text { months, or treatment with bevacizumab } \\
\text { within the preceding } 6 \text { weeks. } \\
\mathrm{NA}=\text { not available. }\end{array}$} \\
\hline
\end{tabular}

patients, it is recommended that patients with cAT be referred for a pharmacist-led drug interaction evaluation, which should be repeated if cancer management changes.

\section{Other Factors to Consider}

\section{Patient Preference and Drug Coverage}

Adherence to therapy has an important effect on the ability of an anticoagulant to prevent vTE recurrence. During therapy selection, consideration of patient preference and drug cost and coverage might help to improve adherence. However, although patient preference is extremely important, that preference should be evaluated in the context of the patient being fully informed about the efficacy, safety, and potential for interference with chemotherapy of the various therapeutic options. In fact, one study showed that cancer patients consider non-interference with their cancer treatment to be the most important attribute of an anticoagulation therapy, followed by efficacy and safety ${ }^{28}$. Only after they have been assured of those qualities do most patients consider their preference for an oral rather than a parenteral route of administration.

\section{Body Weight}

Little evidence is available about the use of DOACs or LMWHS in cancer patients at the extremes of body weight. The International Society on Thrombosis and Haemostasis recently published guidance about the use of DoAcs in obese patients in the general population ${ }^{29}$. Those recommendations suggest that standard doses of DoAcs should be avoided in patients with a body mass index exceeding $40 \mathrm{~kg} / \mathrm{m}^{2}$ or a weight exceeding $120 \mathrm{~kg}$. If DoAcs are used in such patients, the Society recommends the use of standard DOAC doses, with measurement of peak and trough levels.

Per the approved indication, the dose of the LMwH dalteparin was capped at 18,000 IU daily in both the HOKUSAI vTE Cancer and SELECT-D trials. However, prior studies showed that body mass does not have an important effect on the response to enoxaparin, dalteparin, and tinzaparin for patients weighing up to $144 \mathrm{~kg}, 190 \mathrm{~kg}$, and $165 \mathrm{~kg}$ respectively ${ }^{30-32}$. Furthermore, a meta-analysis of data for 921 patients with a body mass index of $30 \mathrm{~kg} / \mathrm{m}^{2}$ or more showed no increased risk of bleeding in that population compared with non-obese patients who received weight-adjusted, "uncapped" LMwH ${ }^{33}$. Therapeutic weight-adjusted dosing (that is, without capping at 18,000 IU in the case of dalteparin) is therefore suggested if LMWH is the anticoagulant of choice for the management of CAT $^{34}$.

With respect to extremely low body weight, the daily dose of edoxaban was reduced in the HOKUSAI vTE Cancer triall $^{7}$ to $30 \mathrm{mg}$ from $60 \mathrm{mg}$ in patients with a body weight of $60 \mathrm{~kg}$ or less. The product monographs for the other DOACs do not recommend dose reduction with lower body weight ${ }^{25,26}$. Those recommendations should be taken into account when selecting an anticoagulant, with added consideration being given to ethnic differences in weight and body mass index distribution.

\section{Burden of Cancer and Burden of VTE}

As in the case of body weight, few data are available about the effects of the cancer and vTE burden on anticoagulant 
TABLE III Anticancer therapies associated with gastrointestinal (GI) toxicity ${ }^{a}$

\begin{tabular}{|c|c|c|}
\hline Drug class & Agent or agents & Types of toxicity \\
\hline Alkylating agent (in high doses) ${ }^{21}$ & Cyclophosphamide, bendamustine, busulfan, ifosfamide, melphalan & Stomatitis \\
\hline Antimetabolite $^{21}$ & 5-Fluorouracil, cytarabine, floxuridine, methotrexate & Diarrhea, stomatitis \\
\hline Antimitotic agent ${ }^{21}$ & Vinblastine, vincristine & Stomatitis, constipation \\
\hline Checkpoint inhibitor ${ }^{22}$ & $\begin{array}{c}\text { Ipilimumab, nivolumab, pembrolizumab, atezolizumab, } \\
\text { durvalumab, avelumab }\end{array}$ & Colitis, diarrhea \\
\hline \multirow[t]{2}{*}{ EGFR inhibitor ${ }^{22}$} & Cetuximab & Diarrhea \\
\hline & Erlotinib, afatinib, gefitinib & Diarrhea, GI bleeding or perforation \\
\hline Immunomodulating agent ${ }^{21}$ & Interleukin 2 & Stomatitis, colitis \\
\hline MEK inhibitor 22 & Trametinib & Diarrhea \\
\hline Nitrosourea ${ }^{21}$ & Carmustine, lomustine & Diarrhea \\
\hline PI3K inhibitor 22 & Idelalisib & Colitis \\
\hline \multirow[t]{2}{*}{ Topoisomerase inhibitor ${ }^{21}$} & Etoposide & Stomatitis \\
\hline & Irinotecan & Diarrhea, stomatitis \\
\hline VEGF or VEGFR inhibitor ${ }^{22}$ & Axitinib, bevacizumab & GI bleeding or perforation \\
\hline
\end{tabular}

a The list of therapies in the table is incomplete; agents are provided as examples.

EGFR = epidermal growth factor receptor; MEK = mitogen-activated protein kinase kinase; PI3K = phosphatidylinositol-4,5-bisphosphate 3-kinase; $\operatorname{VEGF}(\mathrm{R})=$ vascular endothelial growth factor (receptor).

efficacy and safety ${ }^{11}$. Table $\mathrm{v}$ presents baseline characteristics reflecting cancer burden (for example, metastatic disease, performance status, current anticancer treatment) in the CAT trials. Compared with the DOAC studies (HOKUSAI VTE Cancer and SELECT-D), the LMWH trials (CLOT and САТСH) included a higher proportion of patients with metastatic cancer, symptomatic CAT, and poor performance status $7,8,11,14$. Those differences, together with notable differences in the overall mortality reported from those trials, indicate systematic patient selection for study enrolment and limit cross-study comparison. It is also important to note that patients who required thrombolysis or who underwent filter insertion were excluded from the trials. Whether patients with a greater burden of cancer or thrombosis would benefit more from LMWH or DOAC remains to be studied.

\section{Renal Impairment}

The evidence for the management of СAT in patients with moderate-to-severe renal impairment is limited. A recent post hoc analysis of the CLOT trial found that dalteparin was more effective than VKA in the prevention of VTE recurrence for patients with creatinine clearance of less than $60 \mathrm{~mL} / \mathrm{min}$ ( $p=0.0033)$ and that the two agents had a similar safety profile in that population ${ }^{35}$. Similarly, an a priori-specified analysis of the САТсH trial showed no significant differences in the rates of recurrent vTE or major bleeding whether patients with a creatinine clearance less than $60 \mathrm{~mL} / \mathrm{min}$ were treated with tinzaparin or with $\mathrm{VKA}^{36}$. The HoKusai vTe Cancer study ${ }^{7}$ excluded patients with a creatinine clearance less than $30 \mathrm{~mL} / \mathrm{min}$ and reduced the dose of edoxaban for patients with a creatinine clearance of $30-50 \mathrm{~mL} / \mathrm{min}$. Nonetheless, rates of major bleeding in patients with renal impairment in the HоKUSAI vTE Cancer study were numerically higher for those taking edoxaban compared with those taking dalteparin (Table II) ${ }^{7}$. Thus, LMWH might be preferable to DOAC in patients with CAT and a creatinine clearance of $30-50 \mathrm{~mL} / \mathrm{min}$, especially if additional risk factors for bleeding are present.

\section{Significant GI Surgery or Absorption Disorders}

Given that the DOACs are absorbed through the GI tract, concerns have been raised about their absorption in patients who, because of Gi surgery or other disorders, have a significant reduction of the absorptive surface. Evidence in this regard is limited to case series and isolated case reports. The DOAC product monographs do not provide specific guidance about such patients ${ }^{24-26,37}$. Clinical judgment and caution are thus warranted.

\section{Pre-existing Conditions and Co-medication}

Clinicians should also take into consideration the effects of a patient's pre-existing conditions and concurrent medications with respect to the efficacy and safety of any anticoagulant. For example, impaired hepatic function (that is, bilirubin $>1.5$ times the upper limit of normal or other liver function tests $>3$ times the upper limit of normal) might increase both the risk of thrombotic events and the risk of bleeding, with the latter risk appearing to be related to the presence of gastroesophageal varices ${ }^{38}$.

\section{Reassessing Treatment for Secondary Prophylaxis}

Duration of secondary vTE prophylaxis in the cancer population has not been studied. Prospective studies evaluating anticoagulation therapy beyond the initial 6 months include the DALTECAN, TiCAT, and HOKUSAI VTE Cancer studies $7,39,40$. In the DALTECAN prospective cohort study, 55\% of the 334 patients with VTE and active cancer who were treated with dalteparin completed 6 months of therapy, and 33\% completed 12 months ${ }^{39}$. Therapy beyond 6 months (compared with during the first 6 months) was not associated with an increased risk of major bleeding or recurrent vTE. Similarly, the Ticat study, which evaluated the safety of long-term tinzaparin in 247 patients with CAT, reported no significant 
TABLE IV Common drug-drug interactions with direct factor Xa inhibitors $^{24-27}$

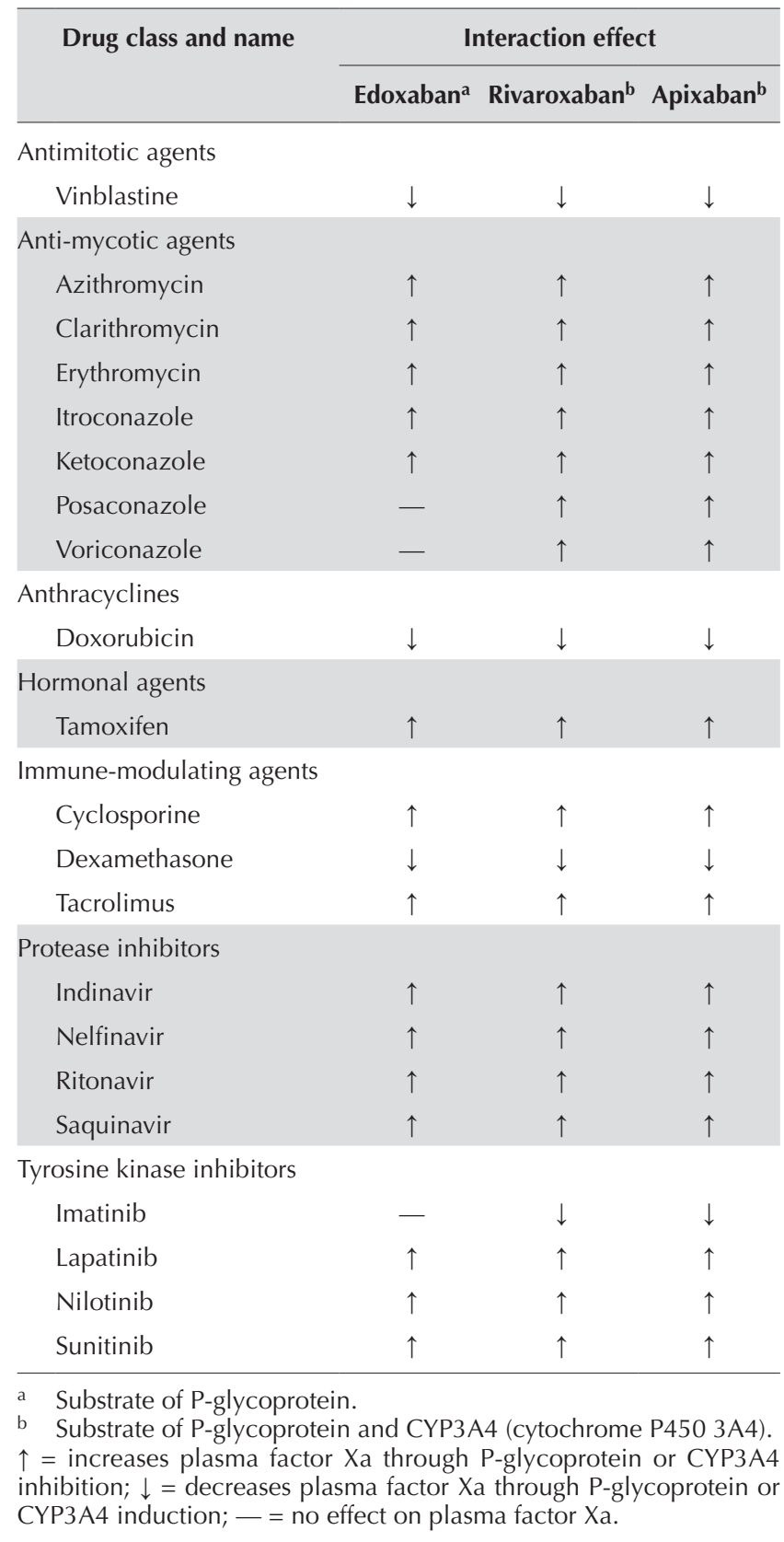

difference in recurrent vTE or clinically relevant bleeding for months $1-6$ compared with months $7-12^{40}$. The HOKUSAI VTE Cancer trial demonstrated acceptable efficacy and safety profiles during the 12-month treatment period ${ }^{7}$. However, the median therapy duration was approximately 6 months, and rates of recurrent VTE and major bleeding beyond the initial 6 months were not reported.

Despite the weak evidence, experts agree that the decision about whether to continue anticoagulation beyond 6 months depends on the patient's cancer status and need for anticancer therapy with thrombogenic potential ${ }^{41}$. Therapy should be assessed on a regular basis (at least every 3 months; sooner, if there are changes in the patient's cancer status or management), and the risk factors for bleeding and vTE recurrence should be simultaneously re-evaluated.

\section{Use of VKA}

Although vkAs are still an available option, their inferior efficacy and associated higher rates of complications mean that their use is strongly discouraged for the acute treatment of CAT, particularly in the first 3 months. Use of a VKA should be reserved for patients in whom LMwHs and DOACs are contraindicated, unaffordable, or unavailable, and for patients who are currently stable while taking such an agent. The vKAs could be reasonable for secondary prevention (beyond 3-6 months), if therapeutic levels can be achieved in the setting of ongoing anticancer therapy and drug-drug interactions.

\section{Upper Extremity and Catheter-Related VTE}

Previous Canadian consensus recommendations suggest that catheter-related cancer-associated DVT requires treatment if the thrombus involves the deep veins (such as the axillary and subclavian) or more proximal veins ${ }^{9}$. Despite the fact that catheter-related upper-extremity vTE is a frequent complication in cancer patients, no head-to-head trials have compared the various types of anticoagulation in this population.

In a small study (74 cancer patients with upperextremity DVT) that was designed to look at catheter survival, treatment with dalteparin and warfarin was shown to be safe and effective, with a vTE recurrence rate of $0 \%$ and a major bleeding event rate of $4 \%$ at 3 months ${ }^{42}$. Similarly, a retrospective cohort study of 89 patients with symptomatic catheter-related upper-extremity vTE treated with 1 month of a full therapeutic dose of LMwH, followed by an intermediate dose of LMWH, reported no recurrent VTE and 2 major bleeding episodes at 3 months ${ }^{43}$. Notably, a prospective cohort study evaluating rivaroxaban monotherapy in 70 cancer patients demonstrated a VTE recurrence rate of $1.43 \%$, including 1 fatal pulmonary embolism, and a total bleeding event rate of $12.9 \%$ at 12 weeks $^{44}$. Considering that the parenteral anti-factor Xa inhibitor fondaparinux has also been reported to be less effective than LMWH in preventing catheter-related thrombosis ${ }^{45}$, routine use of DOACs for catheter-related vTE is discouraged, especially if the catheter remains in situ.

Thus, anticoagulation therapy options for cancer patients with catheter-related upper-extremity DVT include warfarin, LMwH monotherapy, and DoAcs. Based on the evidence available, the consensus group favours therapeutic-dose LMwH monotherapy in preference to DOACs and warfarin. It is recommended that all the other factors discussed in this paper be considered when making a therapeutic decision.

Little evidence is available to guide clinicians with respect to the duration of anticoagulation. Previous guidance has suggested continuing anticoagulation for a minimum of 3 months and, in patients with ongoing risk factors, for the duration that the catheter remains in place ${ }^{46}$.

\section{ACKNOWLEDGMENTS}

This initiative was funded by an unrestricted grant from Pfizer Canada Inc. The authors administered all aspects of the meetings, 
TABLE V Baseline characteristics of selected randomized controlled trials for the acute treatment of cancer-associated thrombosis

\begin{tabular}{|c|c|c|c|c|c|c|c|c|}
\hline \multirow[t]{3}{*}{ Characteristic } & \multicolumn{8}{|c|}{ Reference (study name) } \\
\hline & \multicolumn{2}{|c|}{$\begin{array}{l}\text { Lee et al., } 2003^{11} \\
\text { (CLOT) }\end{array}$} & \multicolumn{2}{|c|}{$\begin{array}{l}\text { Lee et al., } 2015^{14} \\
\text { (CATCH) }\end{array}$} & \multicolumn{2}{|c|}{$\begin{array}{c}\text { Raskob et al., } 2018^{7} \\
\text { (HOKUSAI VTE Cancer) }\end{array}$} & \multicolumn{2}{|c|}{$\begin{array}{l}\text { Young et al., } 2018^{8} \\
\quad \text { (SELECT-D) }\end{array}$} \\
\hline & Dalteparin & Warfarin & Tinzaparin & Warfarin & Edoxaban & Dalteparin & Rivaroxaban & Dalteparin \\
\hline Age (years) & 62 & 63 & 59.7 & 58.8 & 64.3 & 63.7 & 67 & 67 \\
\hline Metastatic cancer (\%) & 66 & 68.6 & 66 & 63.3 & 52.4 & 53.4 & 58 & 58 \\
\hline Cancer therapy (\%) & 78.7 & 76.6 & 50.8 & 55 & 71.6 & 63.1 & 69 & 70 \\
\hline ECOG PS 2 (\%) & 34.9 & 36.1 & 23.6 & 22.8 & 23.6 & 23.7 & 26 & 21 \\
\hline Top 3 cancer types & $\begin{array}{r}\text { Bre } \\
\text { Colo } \\
\text { Lu }\end{array}$ & ctal & $\begin{array}{r}\text { Gynec } \\
\text { Color } \\
\text { Uppe }\end{array}$ & $\begin{array}{l}\text { logic } \\
\text { ctal } \\
\text { GI }\end{array}$ & $\begin{array}{r}\text { Colc } \\
\text { Li } \\
\text { Genit }\end{array}$ & $\begin{array}{l}\text { ectal } \\
\text { ng } \\
\text { urinary }\end{array}$ & $\begin{array}{r}\text { Color } \\
\text { Lur } \\
\text { Bre }\end{array}$ & $\begin{array}{l}\text { ectal } \\
\text { gg } \\
\text { ast }\end{array}$ \\
\hline
\end{tabular}

ECOG PS = Eastern Cooperative Oncology Group performance status; GI = gastrointestinal.

and the funding source had no role in drafting, editing, or approving the treatment algorithm or manuscript. Rebecca Cowan of MedPlan Communications Inc. is thanked for editorial support in the preparation of the manuscript.

\section{CONFLICT OF INTEREST DISCLOSURES}

We have read and understood Current Oncology's policy on disclosing conflicts of interest, and we declare the following interests: MCa has received research funding from Bristol-Myers Squibb, Leo Pharma, and Pfizer, and honoraria from Bayer, Bristol-Myers Squibb/Pfizer, Leo Pharma, Sanofi, Pfizer, and Servier; AYYL has received research funding from Bristol-Myers Squibb and consultancy fees or honoraria from Bayer, Leo Pharma, Pfizer, and Servier; VT has received research funding from Pfizer and Sanofi and honoraria from Bayer, Bristol-Myers Squibb, Leo Phama, Pfizer, Sanofi, and Servier; CW has received honoraria from Bristol-Myers Squibb/Pfizer, Leo Pharma, and Pfizer, and has served as a local principal investigator for studies that have received funding or support from Bayer, Bristol-Myers Squibb/Pfizer, and Daiichi Sankyo; MCr has received grant support, consulting fees, and drugs supplied for a study from Bayer; advisory board fees from Octapharma, Shionogi, and Bristol-Myers Squibb/Pfizer; fees for preparation and presentation of educational materials from Pfizer, Alexion, and Boehringer Ingelheim; advisory board fees, fees for serving on a steering committee, and travel support from Portola; and grant support from Leo Pharma; GLG has received grants from Portola Pharmaceuticals, was a co-investigator for trials conducted by Boehringer Ingelheim, Pfizer, GlaxoSmithKline, Bristol-Myers Squibb, Leo Pharma, Daiichi Sankyo, and Bayer, and has received honoraria from Bayer, Pfizer, GlaxoSmithKline, Leo Pharma, Sanofi, and bioMerieux outside the submitted work. The remaining authors have no conflicts to disclose.

\section{AUTHOR AFFILIATIONS}

*Department of Medicine, Ottawa Hospital Research Institute, University of Ottawa, Ottawa, ON; ${ }^{\dagger}$ Department of Medicine, Centre hospitalier de l'Université de Montréal, Montreal, QC; ${ }^{\ddagger}$ Department of Medicine, McMaster University, Hamilton, ON; ${ }^{\S}$ Department of Oncology, Sir Mortimer B. Davis Jewish General Hospital, McGill University, Montreal, QC; "Department of Hematology, Royal University Hospital, Saskatoon, SK; ${ }^{\#}$ Department of Medicine, QEII Health Sciences Centre, Dalhousie University, Halifax, NS; **Department of Medicine, Centre for Clinical Epidemiology, Lady Davis Institute for Medical Research, Montreal, $\mathrm{QC} ;{ }^{\dagger \dagger}$ Department of Medicine, University of Alberta, Edmonton, $\mathrm{AB}$; ${ }^{\ddagger \ddagger}$ Department of Medicine, University of British Columbia, BC Cancer, Vancouver, BC.

\section{REFERENCES}

1. Horsted F, West J, Grainge MJ. Risk of venous thromboembolism in patients with cancer: a systematic review and meta-analysis. PLoS Med 2012;9:e1001275.

2. Khorana AA, Francis CW, Culakova E, Kuderer NM, Lyman GH. Frequency, risk factors, and trends for venous thromboembolism among hospitalized cancer patients. Cancer 2007;111:2339-46.

3. Prandoni P, Lensing AW, Piccioli A, et al. Recurrent venous thromboembolism and bleeding complications during anticoagulant treatment in patients with cancer and venous thrombosis. Blood 2002;100:3484-8.

4. Sorensen HT, Mellemkjaer L, Olsen JH, Baron JA. Prognosis of cancers associated with venous thromboembolism. NEngl J Med 2000;343:1846-50.

5. Lyman GH, Bohlke K, Khorana AA, et al. on behalf of the American Society of Clinical Oncology. Venous thromboembolism prophylaxis and treatment in patients with cancer: American Society of Clinical Oncology clinical practice guideline update 2014. J Clin Oncol 2015;33:654-6.

6. Kearon C, Akl EA, Ornelas J, et al. Antithrombotic therapy for VTE disease: Chest guideline and expert panel report. Chest 2016;149:315-52.

7. Raskob GE, van Es N, Verhamme P, et al. on behalf of the Hokusai vTE Cancer Investigators. Edoxaban for the treatment of cancer-associated venous thromboembolism. NEngl J Med 2018;378:615-24.

8. Young AM, Marshall A, Thirlwall J, et al. Comparison of an oral factor Xa inhibitor with low molecular weight heparin in patients with cancer with venous thromboembolism: results of a randomized trial (SELECT-D). JClin Oncol 2018;36:2017-23.

9. Carrier M, Lazo-Langner A, Shivakumar S, et al. Clinical challenges in patients with cancer-associated thrombosis: Canadian expert consensus recommendations. Curr Oncol 2015;22:49-59.

10. Meyer G, Marjanovic Z, Valcke J, et al. Comparison of lowmolecular-weight heparin and warfarin for the secondary prevention of venous thromboembolism in patients with cancer: a randomized controlled study. Arch Intern Med 2002;162:1729-35.

11. LeeAY, Levine MN, Baker RI, et al. on behalf of the cLOT investigators. Low-molecular-weight heparin versus a coumarin for the prevention of recurrent venous thromboembolism in patients with cancer. N Engl J Med 2003;349:146-53.

12. Deitcher SR, Kessler CM, Merli G, Rigas JR, Lyons RM, Fareed J on behalf of the ONCENOX investigators. Secondary prevention of venous thromboembolic events in patients with active 
cancer: enoxaparin alone versus initial enoxaparin followed by warfarin for a 180-day period. Clin Appl Thromb Hemost 2006;12:389-96.

13. Hull RD, Pineo GF, Brant RF, et al. on behalf of the LITE trial investigators. Long-term low-molecular-weight heparin versus usual care in proximal-vein thrombosis patients with cancer. Am J Med 2006;119:1062-72.

14. Lee AYY, Kamphuisen PW, Meyer G, et al. on behalf of the САтсH investigators. Tinzaparin vs warfarin for treatment of acute venous thromboembolism in patients with active cancer: a randomized clinical trial. JAMA 2015;314:677-86.

15. McBane Ii R, Loprinzi CL, Ashrani A, et al. Apixaban and dalteparin in active malignancy associated venous thromboembolism. The ADAM vTE trial. Thromb Haemost 2017;117:1952-61.

16. Carrier M, Cameron C, Delluc A, Castellucci L, Khorana AA, Lee AY. Efficacy and safety of anticoagulant therapy for the treatment of acute cancer-associated thrombosis: a systematic review and meta-analysis. Thromb Res 2014;134:1214-19.

17. Vedovati MC, Germini F, Agnelli G, Becattini C. Direct oral anticoagulants in patients with vTE and cancer: a systematic review and meta-analysis. Chest 2015;147:475-83.

18. Lee AYY. When can we stop anticoagulation in patients with cancer-associated thrombosis? Blood 2017;: [Epub ahead of print].

19. Kearon C, AklEA, Comerota AJ, et al. Antithrombotic therapy for vTE disease: Antithrombotic Therapy and Prevention of Thrombosis, 9th ed:American College of Chest Physicians evidence-based clinical practice guidelines. Chest 2012;141(suppl):e419S-96S.

20. Nieto JA, Solano R, Ruiz-Ribó MD, et al. on behalf of the RIETE investigators. Fatal bleeding in patients receiving anticoagulant therapy for venous thromboembolism: findings from the RIETE registry. J Thromb Haemost 2010;8:1216-22.

21. Remesh A. Toxicities of anticancer drugs and its management. Int J Basic Clin Pharmacol 2012;1:2-12.

22. Kroschinsky F, Stölzel F, von Bonin S, et al. on behalf of the iснор Collaborative Group. New drugs, new toxicities: severe side effects of modern targeted and immunotherapy of cancer and their management. Crit Care 2017;21:89.

23. Abraham NS. Prevention of gastrointestinal bleeding in patients receiving direct oral anticoagulants. Am J Gastroenterol Suppl 2016;3:2-12.

24. Servier Canada. Lixiana: Edoxaban Tablets [product monograph]. Laval, QC: Servier Canada; 2017.

25. Bayer. Xarelto: Rivaroxaban Tablet [product monograph]. Mississauga, ON: Bayer; 2018.

26. Pfizer Canada and Bristol-Myers Squibb Canada. Eliquis: Apixaban Tablets [product monograph]. Montreal, QC: Pfizer Canada and Bristol-Myers Squibb Canada; 2018.

27. Lee AY, Peterson EA. Treatment of cancer-associated thrombosis. Blood 2013;122:2310-17.

28. Noble S, Matzdorff A, Maraveyas A, Holm MV, Pisa G. Assessing patients' anticoagulation preferences for the treatment of cancer-associated thrombosis using conjoint methodology. Haematologica 2015;100:1486-92.

29. Martin K, Beyer-Westendorf J, Davidson BL, Huisman MV, Sandset PM, Moll S. Use of the direct oral anticoagulants in obese patients: guidance from the ssc of the IsTH. J Thromb Haemost 2016;14:1308-13.

30. Becker RC, Spencer FA, Gibson M, et al. on behalf of the TIMI $11 \mathrm{~A}$ investigators. Influence of patient characteristics and renal function on factor Xa inhibition pharmacokinetics and pharmacodynamics after enoxaparin administration in non-ST-segment elevation acute coronary syndromes. Am Heart J 2002;143:753-9.
31. Wilson SJ, Wilbur K, Burton E, Anderson DR. Effect of patient weight on the anticoagulant response to adjusted therapeutic dosage of low-molecular-weight heparin for the treatment of venous thromboembolism. Haemostasis 2001;31:42-8.

32. Hainer JW, Barrett JS, Assaid CA, et al. Dosing in heavyweight/obese patients with the LMwH, tinzaparin: a pharmacodynamic study. Thromb Haemost 2002;87:817-23.

33. Garcia DA, Baglin TP, Weitz JI, Samama MM. Parenteral anticoagulants: Antithrombotic Therapy and Prevention of Thrombosis, 9th ed: American College of Chest Physicians evidence-based clinical practice guidelines. Chest 2012;141:e24S-43S. [Errata in: Chest 2012;141:1369 and Chest 2013;144:721—dosage error in article text]

34. Easaw JC, Shea-Budgell MA, Wu CMJ, et al. Canadian consensus recommendations on the management of venous thromboembolism in patients with cancer. Part 2: treatment. Curr Oncol 2015;22:144-55.

35. Woodruff S, Feugère G, Abreu P, Heissler J, Ruiz MT, Jen F. A post hoc analysis of dalteparin versus oral anticoagulant (VKA) therapy for the prevention of recurrent venous thromboembolism (rVTE) in patients with cancer and renal impairment. J Thromb Thrombolysis 2016;42:494-504.

36. Bauersachs R, Lee AYY, Kamphuisen PW, et al. Renal impairment, recurrent venous thromboembolism and bleeding in cancer patients with acute venous thromboembolismanalysis of the CATCH study. Thromb Haemost 2018;118:914-21.

37. Hakeam HA, Al-Sanea N. Effect of major gastrointestinal tract surgery on the absorption and efficacy of direct acting oral anticoagulants (DOACs). J Thromb Thrombolysis 2017;43:343-51.

38. Leonardi F, Maria N, Villa E. Anticoagulation in cirrhosis: a new paradigm? Clin Mol Hepatol 2017;23:13-21.

39. Francis CW, Kessler CM, Goldhaber SZ, et al. Treatment of venous thromboembolism in cancer patients with dalteparin for up to 12 months: the DALTECAN study. J Thromb Haemost 2015;13:1028-35.

40. Jara-Palomares L, Solier-Lopez A, Elias-Hernandez T, et al. Tinzaparin in cancer associated thrombosis beyond 6 months: Ticat study. Thromb Res 2017;157:90-6.

41. Prandoni P, Lensing AW, Piccioli A, et al. Recurrent venous thromboembolism and bleeding complications during anticoagulant treatment in patients with cancer and venous thrombosis. Blood 2002;100:3484-8.

42. Kovacs MJ, Kahn SR, Rodger M, et al. A pilot study of central venous catheter survival in cancer patients using lowmolecular-weight heparin (dalteparin) and warfarin without catheter removal for the treatment of upper extremity deep vein thrombosis (The Catheter Study). J Thromb Haemost 2007;5:1650-3.

43. Delluc A, Le Gal G, Scarvelis D, Carrier M. Outcome of central venous catheter associated upper extremity deep vein thrombosis in cancer patients. Thromb Res 2015;135:298-302.

44. Davies GA, Lazo-Langner A, Gandara E, et al. A prospective study of rivaroxaban for central venous catheter associated upper extremity deep vein thrombosis in cancer patients (Catheter 2). Thromb Res 2018;162:88-92.

45. Mehta SR, Granger CB, Eikelboom JW, et al. Efficacy and safety of fondaparinux versus enoxaparin in patients with acute coronary syndromes undergoing percutaneous coronary intervention: results from the oAsis-5 trial. J Am Coll Cardiol 2007;50:1742-51.

46. Zwicker JI, Connolly G, Carrier M, Kamphuisen PW, Lee AY. Catheter-associated deep vein thrombosis of the upper extremity in cancer patients: guidance from the ssc of the ISTH. J Thromb Haemost 2014;12:796-800. 